\title{
Sustainability Living: Role of Emotions (An Abstract)
}

\author{
Menuka Jayaratne, Gillian Sullivan Mort, and Clare D'Souza
}

\begin{abstract}
Emotions constitute an important dynamic of human action, and in consumer research emotions have been found to influence consumer action. This paper discusses the research study conducted to investigate emotions in sustainability living. Sustainability living is a challenge, and while emotions in ethical behavior have begun to be investigated, little research has been undertaken into the role of emotions in sustainability, except for some work on the negative emotion of guilt. A qualitative study was undertaken with a triangulation approach. Dark green consumer's emotions were investigated in three ways: first spontaneous emotional reactions to pictorial stimulus about sustainability, then the state of sustainability, and finally in relation to their own purchases and practices in sustainability living. This paper contributes by uncovering the role of positive as well as negative emotions in sustainability and the role of emotional regulation in consumer behavior in this domain. Future research directions are discussed.
\end{abstract}

References Available Upon Request

M. Jayaratne $(\bowtie) \bullet$ G.S. Mort $\bullet$ C. D'Souza

La Trobe University, Melbourne, VIC, Australia

e-mail:menuka.jayaratne@latrobe.edu.au; g.sullivan-mort@Latrobe.edu.au; cdsouza@

latrobe.edu.au 